\title{
AugMented Reality in MARKETING - State OF ART
}

\author{
Ksenija Mitrovic, Nebojsa Novakovic, Jelena Spajic \& Ilija Cosic
}
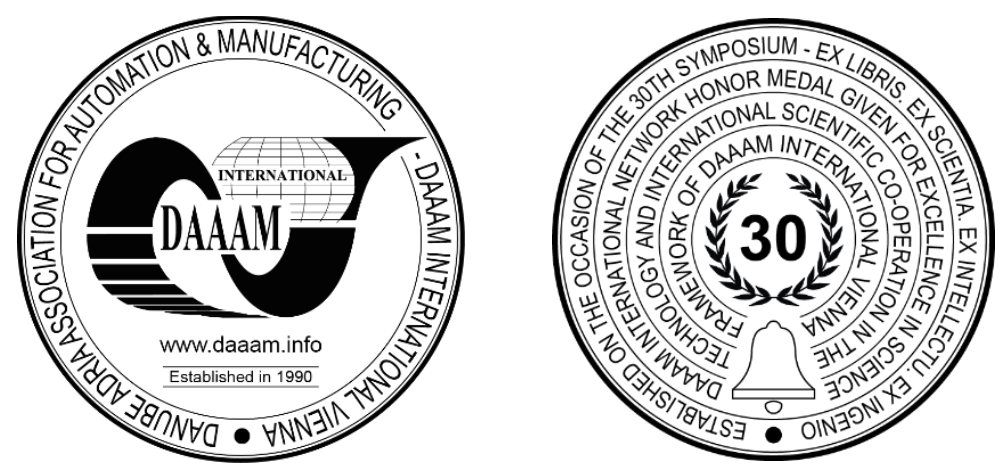

This Publication has to be referred as: Mitrovic, K[senija]; Novakovic, N[ebojsa]; Spajic, J[elena] \& Cosic, I[lija] (2021). Augmented Reality in Marketing - State of Art, Proceedings of the 32nd DAAAM International Symposium, pp.0566-0575, B. Katalinic (Ed.), Published by DAAAM International, ISBN 978-3-902734-33-4, ISSN 1726-9679, Vienna, Austria

DOI: $10.2507 / 32$ nd.daaam.proceedings.081

\begin{abstract}
Digitalization influenced significant changes in marketing activities, giving them a digital form. Implementing Augmented Reality (AR) technology aims to create a competitive advantage and better engage (potential) consumers. With growing usage of digital technologies in the field of marketing, the literature on Augmented Reality in marketing is accumulating. This paper aims to consolidate and organize the literature on the use of AR technology in marketing, providing a comprehensive state of the art review. Existing literature published from 2016 to May 2021 is reviewed and analyzed. As the result, the paper deepens an understanding of different applications of Augmented Reality in marketing. The resulting framework provides future research directions.
\end{abstract}

Keywords: Augmented Reality; Marketing; Systematic literature review; Digitalization

\section{Introduction}

Consumers' adoption of the practice to harness digital information resulted in a surge of new Augmented Reality (AR) applications in many different fields [1]. Marketers commonly seek opportunities to enrich the intensity of emotional responses to attract consumers. Therefore, Augmented Reality is recognized as one of the most disruptive new technologies in the field of marketing [2]. It enables greater consumer involvement [1], using interaction to promote consumer responses [3]. By scanning a brand's logo or a different image, users can access additional content or experience a digital product [4]. This paper aims to present the benefits and functions discovered in the context of using Augmented Reality in marketing. Technological progress facilitates the promotion of the products more interactively [5] putting AR to become a subject of interest among marketers.

Hence, AR marketing as a strategic concept opens the questions to which the researchers are encouraged to answer [6]. Augmented reality has become established research field, and its utilization in marketing activities has received great interest in both academic and managerial literature [7]. A systematic literature review was applied to identify the state of art and address the directions for future work. After a short overview of AR technology and its usage in marketing, the benefits, attributes, and application fields will be presented. In a result, we suggest courses for future research that would enrich the existing literature. 


\section{Augmented Reality (in) Marketing}

AR places users in an environment that is enriched with simulated objects, views, or creatures added to the frame of their actual surroundings [8]. It provides consumers with the resources to visualize and assess products via their smart devices in real-time [9]. Covering the physical world with digital information is a key feature of this technology [1]. Superimposing virtual content into the physical environment [4] gives many opportunities to marketers. AR provides a realistic atmosphere that can be useful to online consumers. In a technology-supported setting, they can create their virtual self while enjoying an enhanced shopping experience [10].

Augmented Reality Marketing presents a digital marketing technology applied in physical settings [11]. However, Rauschnabel et al. (2019) differentiate AR marketing from other digital marketing forms, suggesting it is a long-term strategic capability [3]. Chylinski et al. (2020) define it as "creating digital affordances for consumer experiences" that engage the consumer in a contextually and experientially rich manner [11]. Considering AR as a supportive tool for communication and promotion places this technology on a tactical level. However, AR marketing should extend to strategic research also. Research conducted by Raushnabel [7] gives a radical approach to presenting AR as a potential substitute for a physical world. The results show that AR content can serve as a substitution for utilitarian and digitized products, but the ones that are less symbolic, visible, or decorative.

\section{Methodology}

Given the beneficial effects of AR usage in the marketing context, it is important to theoretically and practically explore how an application of AR technology changes and shapes consumer experience [12]. Systematic Literature Review was applied to examine the level of implementation of AR in the marketing context, analyze relevant studies and synthesize the key findings [13]. The review assists in the derivation of research directions in AR-based marketing [4].

\begin{tabular}{|ll|}
\hline Research protocol & Details description \\
\hline Research online databases & The search was conducted in May 2021 in Scopus and the Web of Science databases. \\
\hline Publication type & $\begin{array}{l}\text { Only peer-reviewed literature was considered. The search was limited to articles, } \\
\text { reviews, and conference proceedings. }\end{array}$ \\
\hline Danguage & The results were limited to the English language. \\
\hline Search fields & Publications from 2016 to May 2021 were considered. \\
\hline Search terms & Titles, abstracts and keywords. \\
\hline Inclusion criteria & $\begin{array}{l}\text {-Scopus: TS = ((“Augmented Reality") OR (“AR") AND ("Marketing”)) } \\
\text { •Web of Science: TS = ((“Augmented Reality") AND ("Marketing")) }\end{array}$ \\
\hline Exclusion criteria & $\begin{array}{l}\text { Only publications that present an AR application in an area related to marketing were } \\
\text { selected. }\end{array}$ \\
\hline Data analysis and synthesis & $\begin{array}{l}\text { Papers with a purely technical focus were excluded. } \\
\text { We analyzed and summarized the content of the papers to explore the level of AR } \\
\text { topic, identify the main gaps and suggest avenues for a future research agenda. }\end{array}$ \\
\hline
\end{tabular}

Table 1. Research protocol

Research protocol (Table 1) from [13] was applied to describe the research process. This paper aims to address the existing level of research applications and outcomes related to AR that can contribute to marketing literature. Relevant articles were searched through Scopus and Web of Science, which are known as reliable databases containing quality papers [14]. After defining the search terms, we made a selection of all the papers that met the research protocol criteria. English language studies published from 2016 to May 2021 were considered for this paper. We limited the search results to articles, reviews, and conference proceedings. To explore and understand the wider context of AR usage in marketing activities, the inclusion criteria covered different aspects of consumer behavior, retail marketing, advertising, tourism marketing, sensory marketing, product marketing, etc.

Figure 1. presents the selection process of papers chosen for the review. In the first phase, 325 papers in Scopus and 402 papers in the Web of Science that appeared in the search results were reviewed based on the paper's abstract and keywords. The search results on the two databases coincided, so the duplicates were removed. In the pre-selection process, we excluded papers that are not in accordance with the research protocol. In the result, 127 papers remained for full-text reading. Excluded papers were mostly technology-oriented and therefore irrelevant for a marketing framework. After full-text reading of the chosen studies, we selected 77 papers eligible for the review. In the final phase, we synthesized the findings of the existing literature. In the result, section 4 presents different applications of researched AR in the marketing context, and also the benefits that AR technology offers to the marketing field. 


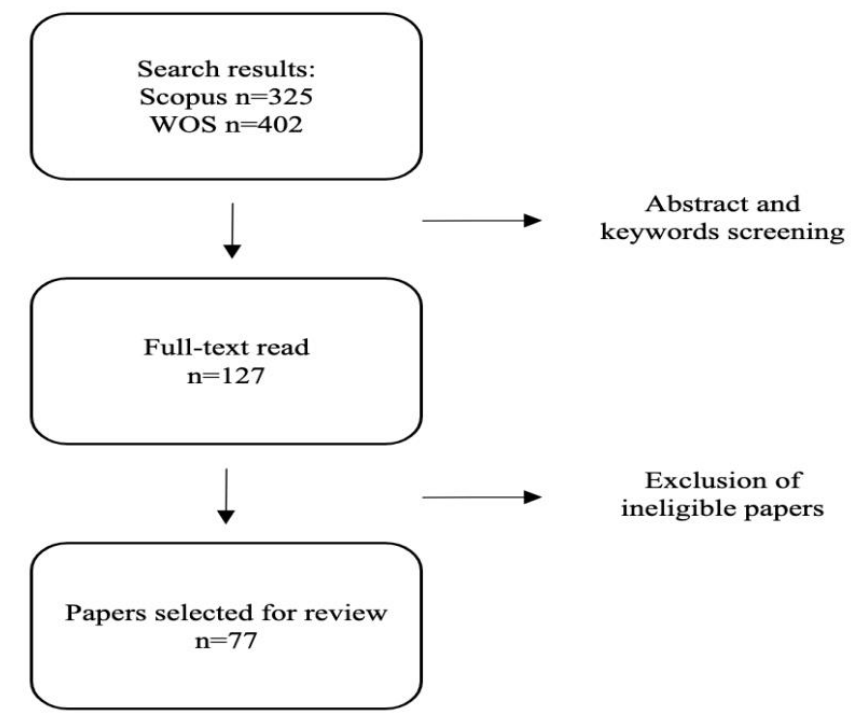

Fig. 1. Selection process

\section{Review results of the $A R$ usage in marketing}

AR enhances marketing [10] by providing authentic, lifelike, and memorable brand experiences [2]. Widely researched fields imply the growing importance of identifying the advantages of using AR technology over traditional forms of media communication. In the result of the conducted systematic literature review, it is concluded that the usage of augmented reality in marketing has the ability to shape consumer behavior [2], [11]. AR marketing changes the marketing focus from attributes of a product to affordances of the situation where engagement creates value [11]. Javornik (2016b) suggests that AR functions can transform experiential activities: product trials, information search, acquisition, and product try-on [4]. Virtual garment try-on has become one of the most promising fields of AR technology usage [15], giving more knowledge and understanding of different features of a product without physically experiencing it [16]. AR is transforming brick and mortar stores into digital showrooms allowing consumers to visualize a product in a desirable virtual context. Virtual representations assist consumers in learning about the product's experiential attributes [17], especially for products that are too big or heavy, expensive, sensitive, and hard to display in every setting [18].

Another form of utilization is personalizing and optimizing the shopping experience with information popping out to locate the product, navigate the store, suggest discounts, promotions, or recommendations [19], [20]. Product attributes are enriched with immersive technology providing reliable information [9], [21]. Researchers examined the level of informativeness, as Javornik suggested [4]. It is revealed that AR enables enhancing the process of the information searching [22], [23], [24], [25], [26]. Overlaying additional information about the product enriches the physical settings and provides more knowledge [27].

Javornik's proposed function related to product trials is useful for risk reduction. Taking into consideration that one of the marketing goals is the enhancing of the likelihood of the purchase, perceived risk should be minimized [27]. AR is proposed as a tool that has the ability to reduce the risk associated with the purchase decision. The ability of testing products in a safe environment reduces the purchasing risks [18], [20], [27]. Moreover, authors suggest that this interactive technology impacts the reduction of other possible risks as well: social, financial, psychological, performance, physical, and time risk [20], [27].

Gallardo et al. (2018) show the capability of AR to improve all the consumer's activities when interacting with the product: selection, adaptation, approval, and purchase [5]. AR marketing has been found useful along a customer journey [1], [29], [30], [31] becoming a new form of its touchpoint [32]. It helps consumers to visualize the product in the pre-purchase stage augmenting beyond usual [9]. Cuomo et al. (2020) found that AR shows great usefulness in terms of brand trust and security [28], since it deepens user's knowledge about the product [32]. Hoyer et al. (2020) suggest that AR has great relevance in the pre-purchase stage with the ability to facilitate imagination and provide a vivid experience of the product [33]. Also, it enriches the experience within the purchase stage and improves postpurchase services by upgrading and enriching consumption [9], [33]. However, the need of future research within the post-purchase phase was proposed, since this phase has the lack of identified benefits of AR. Its opportunities consist of social and experiential benefits that engage users additionally [32].

Also, it is found that Augmented Reality technology has a significant impact on an overall marketing mix [6], [7]. It generates new forms of communication, offers different opportunities for distribution, changes the price of the augmented product, and can improve and extend the core product [6] or even replace it with the virtual one [7]. Carrozzi et al. (2019) suggest that holograms are arising as a new type of digital product [34]. 
Augmented object is not perceived just as a digital copy of a product since it is placed in the user's personal space [35]. Also, consumers are willing to buy more and pay a premium price for products chosen with the support of AR [22], [36].

In several studies an AR application was developed in order to examine the application effect on a specific attribute of consumer behavior [5], [31], [37], [38], [39], [40], [41], [42], [43]. Other studies used existing applications for the same reason, and the AR application IKEA Place was used mostly [1], [3], [36], [44], [45]. Ikea recognized consumer's challenges and insecurities regarding fitting the product in the existing arrangements, enabling consumers to see the virtual furniture right next to the non-augmented objects [46]. For developing new applications, authors used a tool called Vuforia in most cases [31], [38], [47], [48], [49]. In the following section, the variety of the usage of AR in different marketing fields will be presented.

\subsection{AR usage in different marketing fields}

Utilizing AR technology in the field of marketing simplifies contextual relations that are complex to consumers [11]. It is found useful in the retail marketing context [1], [10], [15], [17], [19], [20], [22], [28], [35], [50], [51]. The retail landscape is transforming to omnichannel [28], forcing both consumers and retailers to accept integrated shopping experiences that cover in-store, mobile, and internet shopping [26]. AR is used in this case to extend the possibilities of the physical settings [15]. Retailers have been given the opportunity to reinvent the shopping experience, making it more attractive than traditional. AR effects on consumer behavior are mostly investigated in terms of apparel retailing [21]. The fashion and beauty industry are specific for the need of trying the product before making a buying decision. Therefore, Pantano et al. (2017) explored how AR characteristics influence purchase decisions, using Ray-Ban Virtual Mirror in two different countries. Results show that both samples consider AR as useful and enjoying. While Italians value enjoyment, Germans give priority to the perceived usefulness [15].

AR usage within marketing is mostly covered in the advertising context [29]. The advertising world recognizes AR as a powerful and effective tool. AR empowered ads add life to their 2D stationary match, making them memorable [25] and interactive [47]. Yang et al. (2020) explored AR effectiveness, revealing that AR ads get positive ratings for their creativity, informativeness, and effectiveness The authors found that the effect of AR advertising is mediated by curiosity and attention, with a specified level of familiarity with AR ad technology. It is demonstrated that AR advertising is more effective compared to the traditional one when it comes to influencing user's attitudes toward the ad [52]. Pozharliev et al. (2021) suggest that AR advertising stimulates consumers' emotional responses and positive behavioral intentions [36]. Also, the authors found that it is successful for both novel and traditional products. Divya Udayan et al. (2020) investigated the power of AR to promote brand building compared to a traditional advertisement. Valves are used as an adequate example for trying to bridge the gap between marketing and engineering. Comparing traditional and AR ads, a large number of attributes go in favor of AR: memory retention, product knowledge, novelty, vividness, representational richness [25]. Analyzing different studies of AR usage in advertising [2], [14], [36], [47], [49], [52], [53], it is concluded that AR is a suitable advertising medium.

Brand-related outcomes can benefit from AR [7], since it is revealed that AR is relevant for aiding brand-interactive marketing [54]. AR enables context-aware branding [18], providing extended branded content [28]. Existing research suggests that AR enriches brands, driving direct contact with it [21]. Rauschnabel et al. (2019) proposed a conceptual model for exploring the relationship between consumer perceived benefits and brand attitudes [3]. The authors demonstrated the process of AR influence on a brand. The study revealed that inspiration is a mediating construct between the proposed relationship. Scholz and Duffy (2018) state that AR enables inviting brands into the consumers' personal spaces, resulting in the creation of a strong consumer-brand relationship [35]. With an imprint about the product created in the consumer's mind, brand recall is significantly enhanced [25] and brand attitudes are better communicated. Different aspects of the brand can be enhanced. AR is effective in strengthening the brand's image [5] and boosting brand awareness [20], [50].

Benefits of AR technology are widely recognized in a tourism marketing [31], [43], [55], [56], [57], [58]. Tourism marketing goes beyond giving information but instead immersing tourists in various destinations [43]. Cranmer et al. (2020) investigated the AR value in the tourism sector. Their results show that marketing and sales value were found the most prominent in the tourism industry, regarding AR [57]. Its great marketing potential reflects in the ability to present accurate information and promote destinations with a 'human touch'. Tourism marketing is challenged by distrust of consumers and the need to introduce a destination attractively and credibly [31]. Huertas \& Gonzalo (2020) studied the factors that generate a satisfactory tourist experience in order to contribute to a destination brand. Their results show that AR apps impact satisafction and are able to communicate attributes of a destination brand [58]. While some applications enhance the tourist experience, others facilitate the knowledge related to a specific destination [55]. In this field, museum marketing is also researched [59], [60]. AR enables a vivid world of artifacts and an understanding of its origin and history [31]. Visitors are attracted to museums with the motivation to experience AR technology while exploring the intangible dimensions of a culture or heritage and immersing in the historical spaces. Enjoyment created by the enriched exhibition is expected, along with the vivid original appearance of the monument [60]. 
Avila (2017) suggests that AR found its usage in library marketing too [61]. Augmented technology can be effective in communicating information that exceeds physical signage. Therefore, library communication can become vivid and informational marketing enriched. Technology advancements enabled virtual wine-label technology to deliver unlimited content for wine marketing [62]. Many platforms are designed to connect consumers and wine labels, telling their stories, recommendations, or stimulations that bring labels to life. The authors suggest that the wine industry benefits from AR usage in terms of product promotion, with the great utilization of technology-based storytelling. Implementation of AR technology in the context of sports marketing should be considered as a complementary activity that contributes to the interactivity, but without interfering with the game action. This technology boosts the experience of sports fans which consequently leads to positive word of mouth [63]. There are several studies related to the effectiveness of AR in housing marketing [5], [38], [41], [42]. Traditional catalogues are now outdated and replaced by $3 \mathrm{D}$ visualization of houses in order to assist prospective buyers [41].

Augmenting consumer's surroundings with multiple touch-points enables greater participation and sharing of extended content [28]. Since consumers pursue participation and interaction with brands, generating engaging content comes to focus [32]. Convoy et al. (2019) examined the potential of AR technology in the context of participatory marketing, transforming consumers from passive actors to proactive co-creators [64]. AR technology is considered as innovative way to support sensory marketing [65]. Also, this immersive technology extends the experiential value and has a great significanse in the field of experiential marketing [66]. AR in the context of experiential marketing is recognized as relevant within a tourism sector [66], while it also has the ability to create experiential consumption [22].

\subsection{Researched variables used in AR marketing studies}

AR is reshaping consumer behavior, which demands new strategies to fulfill the upcoming consumer needs [67]. AR attributes: interactivity, vividness, and novelty are used often in the research. However, besides these, different attributes were examined in order to identify their effect on marketing.

\begin{tabular}{|ll|}
\hline Researched variables & References \\
\hline Interactivity & {$[1],[4],[9],[15],[22],[24],[27],[44],[48],[49],[68],[69]$} \\
\hline Engagement & {$[10],[20],[22],[37],[46],[49],[68],[69],[70],[71]$} \\
\hline Usefulness & {$[1],[15],[21],[25],[28],[44],[63],[69]$} \\
\hline Curiosity & {$[49],[52],[70]$} \\
\hline Word of Mouth & {$[17],[30],[63]$} \\
\hline Ease of use & {$[9],[15],[17],[21],[25],[28],[67],[69],[72]$} \\
\hline Attitude & {$[1],[3],[14],[15],[17],[19],[21],[26],[49],[52],[63],[70],[73],[74]$} \\
\hline Satisfaction & {$[2],[9],[10],[17],[24],[35],[49],[56],[58],[71]$} \\
\hline Informativeness & {$[9],[17],[37],[44],[45],[75]$} \\
\hline Control & {$[10],[17],[25],[30],[68],[76]$} \\
\hline Flow & {$[10],[17],[24],[68],[77]$} \\
\hline Purchase intention & {$[2],[14],[20],[28],[35],[44],[45],[56],[73],[74]$} \\
\hline Experience & {$[5],[17],[18],[22],[27],[28],[40],[58],[62],[66],[67],[76]$} \\
\hline Behavioral intentions & {$[14],[15],[17],[21],[23],[26],[28],[44]$,} \\
\hline Enjoyment & {$[10],[15],[17],[23],[24],[69],[76]$} \\
\hline Inspiration & {$[3],[22],[72]$} \\
\hline Vividness & {$[22],[24],[25],[69]$} \\
\hline Novelty & {$[22],[24],[25],[69],[75]$} \\
\hline Customization & {$[22],[34],[71]$} \\
\hline Aesthetic & {$[15],[70],[78]$} \\
\hline Entertainment & {$[22],[24],[59],[70],[75]$} \\
\hline Sense of presence & {$[1],[10],[29],[30],[36],[58],[68],[74]$} \\
\hline Relationship with a brand & {$[17],[36],[49],[51]$} \\
\hline & \\
\hline
\end{tabular}

Table 2. Researched variables in AR marketing

Existing literature is predominantly focused on the acceptance of AR technology [9], [22], and on its technological aspects [15], [22], [32]. Several studies examined technological attributes influence on consumer behavior [15], [32]. 
It is found that this novel technology has a great relevance in supporting the decision making [1], [11], [15], [28], [30], [36], and sales increase [5], [20], [31], [50]. Experience is widely acknowledged by researchers [24] and it is one of the most examined component of AR marketing, as it is shown in Tabel 2. Engagement is also recognized as a beneficial characteristic that is used in many studies. McLean \& Wilson (2019) established the variables relevant for influencing brand engagement. They revealed that AR attributes (interactivity, novelty, and vividness) and technology attributes (perceived ease of use, usefulness, enjoyment and subjective norms) are the drivers of engagement, which consequently results in satisfactory experience.

Mobile AR applications are recognizable for a high level of interactivity, which promises a favorable user experience [9]. Regarding interactivity, Park \& Yo (2020) explored its effects on shopping behavior in mental imagery context. The authors suggest that controllability and playfulness positively influence mental imagery. AR amplifies the interactivity ladder with the brand, but also among users [32]. Greater interactivity is achieved in bringing the brand's offering in a personally relevant context, within the desired environment. Also, it can be supported by getting control over the simulated experience [30]. Qin et al. (2021) found that interactivity affects hedonic and utilitarian values. Nikhahsemi et al. (2021) examined AR attributes relationship with hedonic and utilitarian components. They found that vividness and novelty positively influence both hedonic and utilitarian values. However, interactivity does not exhibit a positive relationship with utilitarian components. On the other hand, Hilken et al. (2017) found a positive relationship between spatial presence and hedonic and utilitarian value perception of the online shopping experience [30]. Results from the research conducted by Pantano et al. (2017) also show that AR is considered a useful and enjoyable tool, thus utilitarian and hedonic values are repetitively recognized [15].

\subsection{Future research agenda}

Authors propose examining the influence of AR on ad format belief, ad trust, and ad message involvement. With the great potential of the usage in advertising, we believe that it is crucial to reveal the consumer responses toward proposed attributes. Also, customization abilities during AR experience should be explored, taking into consideration that it can provide relevant managerial implications. Grzegorczyk et al. (2019) indicate that creating products and services that fulfill consumer desire has great relevance [71]. However, the effects of customized experiences on consumer responses were not examined. Since most studies used students as respondents [79], it is required to broaden the experiment sample to generalize the results. Younger generations the with focus on alpha generation can be an interesting sample to discover the complete potential of using this immersive technology in marketing activities, making them the long-term strategic capability.

\section{Conclusion}

Marketers now have the opportunity to approach and interact with consumers in a more exciting and effective way [10], empowered by technology deployment. It is shown that there is a significant number of papers that examine the usage of AR in the marketing context, which is required given the importance of its benefits. Marketing scholars studied different variables that impact consumer behavior, brand, and acceptance of this technology by consumers. A broad overview should be used as a course in examining a specific topic that is relevant to AR in marketing. This paper summarized the relevant literature and addressed the future research agenda. In the result of reviewing current studies, it is proposed that AR should be considered as a new paradigm in marketing research and practice [6].

\section{Acknowledgments}

Participation in the $32^{\text {nd }}$ DAAAM International Symposium on Intelligent Manufacturing and Automation was supported by The Ministry of Education, Science and Technological Development of the Republic of Serbia.

\section{References}

[1] Alimamy, S. \& Al-Imamy, S. (2021): Customer perceived valuethrough quality augmented reality experiences in retail: The mediating effect of customer attitudes, Journal of Marketing Communications, 27, 1, ISSN 1466-4445

[2] Sung, E. C. (2021). The effects of augmented reality mobile app advertising: Viral marketing via shared social experience. Journal of Business Research, 122, 75-87, ISSN 0148-2963

[3] Rauschnabel, P. A., Felix, R., \& Hinsch, C. (2019). Augmented reality marketing: How mobile AR-apps can improve brands through inspiration. Journal of Retailing and Consumer Services, 49, 43-53, ISSN 0969-6989

[4] Javornik, A. (2016b). Augmented reality: Research agenda for studying the impact of its media characteristics on consumer behaviour. Journal of Retailing and Consumer Services, 30, 252-261, ISSN 0969-6989

[5] Gallardo, C., Rodríguez, S. P., Chango, I. E., Quevedo, W. X., Santana, J., Acosta, A. G., \& Andaluz, V. H. (2018). Augmented reality as a new marketing strategy. International conference on augmented reality, virtual reality and computer graphics, ISBN 978-3-319-95269-7, 351-362, july 2018, Otranto, Italy, Springer, Cham, https://doi.org/10.1007/978-3-319-95270-3_29 
[6] Dwivedi, Y. K., Ismagilova, E., Hughes, D. L., Carlson, J., Filieri, R., Jacobson, J., \& Wang, Y. (2021). Setting the future of digital and social media marketing research: Perspectives and research propositions. International Journal of Information Management, 59, 102168, ISSN 0268-4012

[7] Rauschnabel, P. A. (2021). Augmented reality is eating the real-world! The substitution of physical products by holograms. International Journal of Information Management, 57, 102279, ISSN 0268-4012

[8] Värno, K., Mahmood, K., Otto, T., \& Kuts, V. (2019). Development of a smart workstation by using AR technology. Annals of DAAAM. Proceedings, 30, October 2019, Zadar, Craotia, EU, ISSN 1726-9679, ISBN 978-3-902734-22-8, pp.1061-1067, Katalinic, B. (Ed), DAAAM International, Vienna, Austria, EU, https://doi.org/10.2507/30th.daaam.proceedings.148

[9] Qin, H., Peak, D. A., \& Prybutok, V. (2021). A virtual market in your pocket: How does mobile augmented reality (MAR) influence consumer decision making?. Journal of Retailing and Consumer Services, 58, 102337, ISSN 0969-6989

[10] Huang, T. L., \& Liao, S. L. (2017). Creating e-shopping multisensory flow experience through augmented-reality interactive technology. Internet Research, 27, 2, ISSN 1066-2243

[11] Chylinski, M., Heller, J., Hilken, T., Keeling, D. I., Mahr, D., \& de Ruyter, K. (2020). Augmented reality marketing: A technology-enabled approach to situated customer experience. Australasian Marketing Journal (AMJ), 28, 4, 374-384, ISSN 1441-3582

[12] Loureiro, S. M. C., Guerreiro, J., Eloy, S., Langaro, D., \& Panchapakesan, P. (2019). Understanding the use of Virtual Reality in Marketing: A text mining-based review. Journal of Business Research, 100, 514-530, ISSN 0148-2963

[13] Muñoz-Leiva, F., López, M. E. R., Liebana-Cabanillas, F., \& Moro, S. (2021). Past, present, and future research on self-service merchandising: a co-word and text mining approach. European Journal of Marketing, ISSN 03090566

[14] Yussof, F. M., Salleh, S. M., \& Ahmad, A., L. (2019). Factors of Augmented Reality Technology Adoption in Influencing Attitude and Purchasing Intention: A Review on Advertising Context. International Journal of Advanced Science and Technology, 28, 18, 321 - 328, ISSN 2005-4238

[15] Penco, L., Serravalle, F., Profumo, G., \& Viassone, M. (2020). Mobile augmented reality as an internationalization tool in the "Made In Italy" food and beverage industry. Journal of Management and Governance, 1-31, ISSN $1385-3457$

[16] Sihi, D. (2018). Home sweet virtual home: The use of virtual and augmented reality technologies in high involvement purchase decisions. Journal of Research in Interactive Marketing, ISSN 2040-7122

[17] Perannagari, K. T., \& Chakrabarti, S. (2019). Factors influencing acceptance of augmented reality in retail: insights from thematic analysis. International Journal of Retail \& Distribution Management, ISSN 0959-0552

[18] Habib, A., \& Hakim, A. (2016). Context aware augmentational marketing. 2016 SAI Computing Conference (SAI), july 2016, ISBN 978-1-4673-8461-2, pp.1227-1231, IEEE, London, UK, https://doi.org/10.1109/SAI.2016.7556135

[19] van Esch, P., Arli, D., Gheshlaghi, M. H., Andonopoulos, V., von der Heidt, T., \& Northey, G. (2019). Anthropomorphism and augmented reality in the retail environment. Journal of Retailing and Consumer Services, 49, 35-42, ISSN 0969-6989

[20] Parekh, P., Patel, S., Patel, N. \& Shah, M. (2020). Systematic review and meta-analysis of augmented reality in medicine, retail, and games. Visual Computing of Industry, Biomedicine and Art, 3, 21, ISSN 2096496X

[21] Ross, H. F., \& Harrison, T. (2016). Augmented reality apparel: An appraisal of consumer knowledge, attitude and behavioral intentions. In 2016 49th Hawaii international conference on system sciences (HICSS), january 2016, ISSN 530-1605, ISBN 978-0-7695-5670-3, 3919-3927, IEEE, Koloa, HI, USA, https://doi.org/10.1109/HICSS.2016.487

[22] Nikhashemi, S.R., Knight, H.H., Nusair, K. \& Lian, B. C. (2021) Augmented reaility in smart retailing: A (n) (A) Symmetric Approach to continuous intention to use retail brand's mobile AR apps. Journal of Retailing and Consumer Sevices, 60, 102464, ISSN 0969-6989

[23] Saprikis, V., Avlogiaris, G., \& Katarachia, A. (2021). Determinants of the intention to adopt mobile augmented reality apps in shopping malls among university students. Journal of Theoretical and Applied Electronic Commerce Research, 16, 3, 491-512, ISSN 0718-1876

[24] Barhorst, J. B., McLean, G., Shah, E., \& Mack, R. (2021). Blending the real world and the virtual world: Exploring the role of flow in augmented reality experiences. Journal of Business Research, 122, 423-436, ISSN 0148-2963

[25] Divya Udayan, J., Kataria, G., Yadav, R., \& Kothari, S. (2020). Augmented Reality in Brand Building and Marketing - Valves Industry. 2020 International Conference on Emerging Trends in Information Technology and Engineering (ic-ETITE), ISSN 21570485, Vellore, doi:10.1109/ic-etite47903.2020.425

[26] Park, M., \& Yoo, J. (2020). Effects of perceived interactivity of augmented reality on consumer responses: A mental imagery perspective. Journal of Retailing and Consumer Services, 52, 101912, ISSN 0969-6989

[27] Alimamy, S., Deans, K. R., \& Gnoth, J. (2018). The role of augmented reality in the interactivity ofco-creation: A critical review. International Journal of Technology and Human Interaction (IJTHI), 14, 3, 88-104, ISSN 15483908 
[28] Cuomo, M. T., Tortora, D., Festa, G, Ceruti, F \& Metallo, G. (2020). Managing omni-customer brand experience via augmented reality: A qualitative investigation in the Italian fashion retailing system. Qualitative Market Research, 23, 3, 427-445, ISSN 1352-2752

[29] Wedel, M., Bigné, E., \& Zhang, J. (2020). Virtual and augmented reality: Advancing research in consumer marketing. International Journal of Research in Marketing, 37, 3, 443-465, ISSN 0167-8116

[30] Hilken, T., de Ruyter, K., Chylinski, M., Mahr, D., \& Keeling, D. I. (2017). Augmenting the eye of the beholder: exploring the strategic potential of augmented reality to enhance online service experiences. Journal of the Academy of Marketing Science, 45, 6, 884-905, ISSN 0092-0703

[31] Lin, C. M., Lin, T. C., Lin, Y. C., Wang, C. M., \& Dow, C. R. (2018). Community interaction and marketing using 3D coloring augmented reality in Zhongxing New Village. In 2018 15th International Symposium on Pervasive Systems, Algorithms and Networks (I-SPAN), October 2018, ISBN 978-1-5386-8535-8, pp. 272-276, IEEE, Yichang, China, https://doi.org/10.1109/I-SPAN.2018.00052

[32] Penco, L., Serravalle, F., Profumo, G., \& Viassone, M. (2020). Mobile augmented reality as an internationalization tool in the "Made In Italy" food and beverage industry. Journal of Management and Governance, 1, 31, ISSN 1385-3457

[33] Penco, L., Serravalle, F., Profumo, G., \& Viassone, M. (2020). Mobile augmented reality as an internationalization tool in the "Made In Italy" food and beverage industry. Journal of Management and Governance, 1-31, ISSN $1385-3457$

[34] Carrozzi, A., Chylinski, M., Heller, J., Hilken, T., Keeling, D. I., \& de Ruyter, K. (2019). What's mine is a hologram? How shared augmented reality augments psychological ownership. Journal of interactive marketing, 48, 71-88, ISSN 1094-9968

[35] Scholz, J., \& Duffy, K. (2018). We ARe at home: How augmented reality reshapes mobile marketing and consumer-brand relationships. Journal of Retailing and Consumer Services, 44, 11-23, ISSN 0969-6989

[36] Pozharliev, R., De Angelis, M., \& Rossi, D. (2021). The effect of augmented reality versus traditional advertising: a comparison between neurophysiological and self-reported measures. Marketing Letters, 1, 16, ISSN 0923-0645

[37] Ludwig. T., Hoffmann, S., Jasche, F \& Ruhrmann, M. (2020). VacuumCleanAR: augmented reality-based selfexplanatory physical artifacts. In: Alt, F., Schneegass, S. \& Hornecker, E. (Hrsg.), Mensch und Computer 2020 Tagungsband. pp. 291-302, New York: ACM, doi: 10.1145/3404983.3405526

[38] Adrianto, D., Hidajat, M., \& Yesmaya, V. (2016). Augmented reality using Vuforia for marketing residence. In 2016 1st International Conference on Game, Game Art, and Gamification (ICGGAG), december 2016, ISBN 9781-5090-5480-0, pp. 1-5, IEEE, Jakarta, Indonesia, https://doi.org/10.1109/ICGGAG.2016.8052642

[39] Ajibola, D., Shafombabi, V., Petrus, P., Shilongo, N., Thielen, E., \& Sieck, J. (2018). Using augmented reality to enhance printed magazine articles about Namibian lodges. In Proceedings of the Second African Conference for Human Computer Interaction: Thriving Communities, December 2018, Windhoek, Namibia, ISBN 9781450365581, pp. 1-4, Association for Computing Machinery, New York, NY, United States, https://doi.org/10.1145/3283458

[40] Tsai, T. H., Chang, H. T., Yu, M. C., Chen, H. T., Kuo, C. Y., \& Wu, W. H. (2016). Design of a mobile augmented reality application: An example of demonstrated usability. In International Conference on Universal Access in Human-Computer Interaction, june 2016, ISBN 978-3-319-40243-7, pp. 198-205, Springer, Cham, https://doi.org/10.1007/978-3-319-40244-4_19

[41] Setyadi, R., \& Ranggadara, I. (2020). Augmented reality using features accelerated segment test for property catalogue. Telkomnika, 18, 1, 140-147, ISSN 1693-6930

[42] Mufid, M. R., Tahir, M., Meiyuana, D. B., Dwileksa, A. \& Kumiawaty, E. (2020), Housing design in planet green tambora using augmented reality for promotion media. IES 2020 - International Electronics Symposium: The Role of Autonomous and Intelligent Sustems for Human Life and Comfort. September 2020, ISBN 978-172819580-8, pp. 669-673, doi: 10.1109/IES50839.2020.9231546

[43] Jung, T. H., Lee, H., Chung, N., \& tom Dieck, M. C. (2018). Cross-cultural differences in adopting mobile augmented reality at cultural heritage tourism sites. International Journal of Contemporary Hospitality Management, ISSN 0959-6119

[44] Kowalczuk, P., Siepmann, C., \& Adler, J. (2021). Cognitive, affective, and behavioral consumer responses to augmented reality in e-commerce: A comparative study. Journal of Business Research, 124, 357-373, ISSN 01482963

[45] Haile, T. T., \& Kang, M. (2020). Mobile augmented reality in electronic commerce: investigating user perception and purchase intent amongst educated young adults. Sustainability, 12, 21, 9185, ISSN 2071-1050

[46] Scholz, J., \& Smith, A. N. (2016). Augmented reality: Designing immersive experiences that maximize consumer engagement. Business Horizons, 59, 2, 149-161, ISSN 0007-6813

[47] Wijaya, A. C., Munandar, M. W. A., \& Utaminingrum, F. (2019). Usability testing of augmented reality for food advertisement based on mobile phone using system usability scale. In 2019 International Conference on Sustainable Information Engineering and Technology (SIET), september 2019, ISBN 978-1-7281-3881-7, pp. 266-269, IEEE, Lombok, Indonesia, https://doi.org/10.1109/SIET48054.2019.8986118 
[48] Hing, V., \& Khoo, H. K. (2017). Business card reader with augmented reality engine integration. 9th International Conference on Robotic, Vision, Signal Processing and Power Applications, september 2016, ISBN 978-981-101719-3, pp. 219-227, Springer, Singapore, https://doi.org/10.1007/978-981-10-1721-6_24

[49] Sravanthi, P. V. L. (2021). Litterature review on brand building through augmented reality. International Journal of Modern Agriculture, 10, 2, 595-604, ISSN 2305-7246

[50] Jäger, A. K., \& Weber, A. (2020). Increasing sustainable consumption: message framing and in-store technology. International Journal of Retail \& Distribution Management, ISSN 0959-0552

[51] Ramadan, Z. B., \& Farah, M. F. (2017). The Pokémonisation of the first moment of truth. International Journal of Web Based Communities, 13, 2, 262-277, ISSN 1477-839

[52] Yang, S., Carlson, J. R., \& Chen, S. (2020). How augmented reality affects advertising effectiveness: The mediating effects of curiosity and attention toward the ad. Journal of Retailing and Consumer Services, 54, 102020. ISSN 0969-6989

[53] de Ruyter, K., Heller, J., Hilken, T., Chylinski, M., Keeling, D. I., \& Mahr, D. (2020). Seeing with the customer's eye: Exploring the challenges and opportunities of AR advertising. Journal of Advertising, 49, 2, 109-124, ISSN 0091-3367

[54] Ng, C. C., \& Ramasamy, C. (2018). Augmented reality marketing in Malaysia-future scenarios. Social Sciences, $7,11,224$, ISSN 20760760

[55] Lacka, E. (2020). Assessing the impact of full-fledged location-based augmented reality games on tourism destination visits. Current Issues in Tourism, 23, 3, 345-357, ISSN 1368-3500

[56] Ashraf, F., \& Nagy, G. (2019). HBIM as a tool for branding historical Egyptian sites by utilizing augmented reality. In IOP Conference Series: Earth and Environmental Science, november 2017, New Cairo, Egypt, ISBN 17551307 IOP Publishing, https://doi.org/10.1088/1755-1315/397/1/012012

[57] Cranmer, E. E., tom Dieck, M. C., \& Fountoulaki, P. (2020). Exploring the value of augmented reality for tourism. Tourism Management Perspectives, 35, 100672, ISSN 2211-9736

[58] Huertas, A., \& Gonzalo, J. (2020). The role of augmented reality in destination branding. Tourism and hospitality management, 26, 2, 419-436, ISSN 1330-7533

[59] Nechita, F., \& Rezeanu, C. I. (2019). Augmenting museum communication services to create young audiences. Sustainability, 11, 20, 5830, ISSN 2071-1050

[60] Recupero, A., Talamo, A., Triberti, S., \& Modesti, C. (2019). Bridging museum mission to visitors' experience: activity, meanings, interactions, technology. Frontiers in psychology, 10, 2092, ISSN 1664-1078

[61] Avila, S. (2017). Implementing augmented reality in academic libraries. Public Services Quarterly, 13, 3, 190-199, ISSN 15228959

[62] Vrigkas, M., Lappas, G., Kleftodimos, A., \& Triantafillidou, A. (2021). Augmented reality for wine industry: Past, Present, and Future. In SHS Web of Conferences, may 2021, ISSN 2261-2424, 04006, EDP Sciences, https://doi.org/10.1051/shsconf/202110204006

[63] Goebert, C., \& Greenhalgh, G. P. (2020). A new reality: Fan perceptions of augmented reality readiness in sport marketing. Computers in Human Behavior, 106, 106231, ISSN 0747-5632

[64] Conway, N., Soro, A., Brown, R., \& Turkay, S. (2019). Exploring uses of augmented reality in participatory marketing. In Extended Abstracts of the 2019 CHI Conference on Human Factors in Computing Systems, May 2019, Glasgow, Scotland Uk, Association for Computing Machinery, New York, NY, United States, pp. 1-6, ISBN 9781450359719, https://doi.org/10.1145/3290607.3313086

[65] Crofton, E. C., Botinestean, C., Fenelon, M., \& Gallagher, E. (2019). Potential applications for virtual and augmented reality technologies in sensory science. Innovative Food Science \& Emerging Technologies, 56, 102178, ISSN 1466-8564

[66] Kavran, A. K., Lončarić, D. \& Dlacic, J. (2016). Augmented reality experiential marketing in tourism. 5th International Scientific Symposium Economz of Eastern Croatia - Vision and Growth, june 2016, Osijek, ISSN $1848-9559$

[67] Wiebach, N., \& Send, H. (2019). Augmented Reality Shopping Services: Key Factors Affecting Customer Evaluation and Acceptance. 14th European Conference on Innovation and Entrepreneurship, ECIE 2019, September 2019, 1111-1118, ISBN 20491050, ISBN 978-191276434-1

[68] Javornik, A. (2016a). Augmented reality: Research agenda for studying the impact of its media characteristics on consumer behaviour. Journal of Retailing and Consumer Services, 30, 252-261, ISSN 0969-6989

[69] McLean, G., \& Wilson, A. (2019). Shopping in the digital world: Examining customer engagement through augmented reality mobile applications. Computers in Human Behavior, 101, 210-224, ISSN0747-5632

[70] Dodoo, N. A., \& Youn, S. (2021). Snapping and chatting away: Consumer motivations for and outcomes of interacting with Snapchat AR ad lens. Telematics and Informatics, 57, 101514, ISSN 0736-5853

[71] Grzegorczyk, T., Sliwinski, R., \& Kaczmarek, J. (2019). Attractiveness of augmented reality to consumers. Technology Analysis \& Strategic Management, 31, 11, 1257-1269, ISSN 0953-7325

[72] Hinsch, C., Felix, R., \& Rauschnabel, P. A. (2020). Nostalgia beats the wow-effect: Inspiration, awe and meaningful associations in augmented reality marketing. Journal of Retailing and Consumer Services, 53, 101987, ISSN 0969-6989 
[73] Phua, J., \& Kim, J. J. (2018). Starring in your own Snapchat advertisement: Influence of self-brand congruity, selfreferencing and perceived humor on brand attitude and purchase intention of advertised brands. Telematics and Informatics, 35, 5, 1524-1533, ISSN 0736-5853

[74] Arlati, S., Spoladore, D., Baldassini, D., Sacco, M., \& Greci, L. (2018). VirtualCruiseTour: An AR/VR application to promote shore excursions on cruise ships. In International Conference on Augmented Reality, Virtual Reality and Computer Graphics, July 2018, pp. 133-147, ISBN 978-3-319-95269-7, Springer, Cham, https://doi.org/10.1007/978-3-319-95270-3_9

[75] Feng, Y., \& Xie, Q. (2018). Measuring the content characteristics of videos featuring augmented reality advertising campaigns. Journal of Research in Interactive Marketing, ISSN 2040-7122

[76] Irshad, S., \& Awang, D. R. B. (2016). User perception on mobile augmented reality as a marketing tool. 2016 3rd International Conference on Computer and Information Sciences (ICCOINS), august 2016, Kuala Lumpur, Malaysia, ISBN 978-1-5090-2550-3, pp.109-113, IEEE, https://doi.org/10.1109/ICCOINS.2016.7783198

[77] Shin, M. H., Lee, Y. M., \& Kim, J. H. (2019). Impact factors analysis on AR shopping services immersion. The Journal of Distribution Science, 17, 12, 13-21, ISSN 1738-3110

[78] Vongurai, R. (2021). Factors influencing experiential value toward using cosmetic AR try-on feature in Thailand. Journal of Distribution Science, 19, 1, 75-87, ISSN 1738-3110

[79] Shahab, M. H., Ghazali, E. \& Mohtar, M. (2021). The role of elaboration likelihood model in consumer behavior research and its extension to new technologies: A review and future research agenda. International Journal of Consumer Studies, ISSN 14706423 